Original Contribution

\title{
STUDY OF ELEMENTS OF INTEGRATED FERTILIZER SYSTEMS IN GLASSHOUSE CUCUMBER
}

\author{
B. Arnaoudov*, H. Boteva, Ts. Dintcheva \\ Maritsa Vegetable Crops Research Institute. Plovdiv, Bulgaria
}

\begin{abstract}
The current study goal is to determine the influence of some organic fertilizers over the growth and the productive qualities of the glasshouse cucmbers grown as a substrate culture. The experimental work was conducted in non-heated glasshouse Venlo type in Maritza VCRI Plovdiv with Defense cucumber variety (EZ). Adding Humustim to the nutrition regime of the glasshouse cucumbers increases the first quality production $(99550 \mathrm{~kg} / \mathrm{ha})$. The quantity of the yield from second quality was not influenced by the use of the studied fertilizing bioproducts. The treatment with Humustim did not significantly increase the total yield in comparison with the conventional fertilization but there was considerable higher influence over the productivity among the rest of the fertilizing bioproducts. As a result of adding the organic fertilizers to the nutrition regime the percentage distribution of the production from first quality was not increased.
\end{abstract}

Key words: cucumbers, glasshouses, bioproducts, substrate culture.

\section{INTRODUCTION}

One of the priorities of the investigation work on a world scale is elaboration of the models for maintaining the nutrition regime as alternative ecological decisions are searched, that correspond to the requirements of the modern agriculture.

The humin compounds compose $65-70 \%$ of the soil organic matter and are subject of investigation due to the multifunctional effect that the give applied in the agriculture.

The humates improve the assimilation of nutrition substances from the plants, improve the soil structure, stimulate the growth, increase the yields from number of vegetable cultures, and improve the quantity of the gained production. The humates are also responsible for changing number of nutrition substances in a form assimilated for the plants $(1,2,5)$.

The fertilizers with amino acids are new type products with great perspectives. Mixtures from amino acids are used for partial substitution of

\footnotetext{
*Correspondence to: Boyan Arnoudov, "Maritsa" Vegetable Crops Research Institute, Plovdiv 4003, 32 Brezovsko shousse str., huan_veron@abv.bg
}

$\mathrm{NO}_{3}$ in many plants. In most cases that substitution leads to decreasing of the nitrate content and increases the content of total nitrogen in salads, Chinese cabbage, onion and other leaf vegetables $(3,4)$.

Different bioproducts are offered on the Bulgarian market, imported or produced from own companies. The studies however are insufficient, for their use in glasshouse vegetable cultures, including in tomatoes. Expanding the studies in our country is necessary to guarantee the effect from the bioproducts application while keeping the environment and its potential for future production.

The current study goal is to determine the influence of some organic fertilizers over the growth and the productive qualities of the glasshouse cucmbers grown as a substrate culture.

\section{MATERIALS AND METHODS}

The experimental work was conducted in nonheated glasshouse Venlo type in Maritza VCRI Plovdiv with Defense $F_{1}$ cucumber variety (EZ). The plants were grown as a soil and substrate culture.

Conditions of the experiment:

Variety: "Defense "F $F_{1}$ (EnzaZaden Netherland) 
Sowing: 16-28. 03.

Planting: 16-22. 04.

Yielding: до 08-10. 08.

Density of sowing: $1.44 \mathrm{plant} / \mathrm{m}^{2}$.

Technology: The variants shown below were brought out on peat-perlite substrate. Svagnum perlite (Lithuania) and agroperlite in volume correlation 1:1 were used for the substrate making. Each container contained $16 \mathrm{~L}$ peatperlite substrate treated with organic fertilizers according to the shown variants.

\section{Variants:}

\section{Control - mineral fertilization \\ 2. Baykal \\ 3. BioOne \\ 4. Tecamin \\ 5. Agriful \\ 6. Humustim \\ 7. Labin Amidoacidos 24\%}

The doses of the studied bioproducts were considered according to the recommendations of the production company.

The growth peak of the plants was removed when reached the height of the supporting wires $(2 \mathrm{~m})$. The experiment was set by the method of the long parcels in 4 repeats.

The plants were grown in peat substrate (svagnum peat: agroperlite 1:1 vol./vol.).

Experiment was conducted in same nutrition background favorable for the cucumber culture. For its maintenance was made basic fertilization of the field with $400 \mathrm{~kg} / \mathrm{h}$ a triple superphosphate and $500 \mathrm{~kg} / \mathrm{ha}$ potassium sulfate and during the period $28^{\text {th }}$ of April $-1^{\text {-st }}$ of August weekly supply with ammonium nitrate and potassium sulfate by $35 \mathrm{~kg} / \mathrm{ha}$.

Indexes of the study:

Microclimate conditions.

At 8.00 o'clock and at 14.00 o'clock were registered:

- air temperature. It was recorded with minimal-maximum thermometer.
ARNAOUDOV B., et al. - substrate temperature in depth of $10 \mathrm{~cm}$.

With soil thermometer

- sunny radiation. With portable luxemeter. - relative humidity

Biometrical analysis. Stem growth and leaf formation pace was determined.

Measurements were made weekly till removing the growth top.

Yield. The production from first quality and the total yield incoming was determined three times a week (Monday, Wednesday and Friday).

Mathematical data processing. Multidirectional comparing analysis by the Duncan method was conducted for the mathematical processing of the obtained material.

\section{RESULTS AND DISCUSSION \\ Growth expressions}

The statistical analysis of the obtained data did not register significant differences in the growth expressions of the experimented variants of glasshouse cucumbers. The values of the studied index vary from $3,74 \mathrm{~cm} / 24 \mathrm{~h}$ in the variant with Baykal to $4,46 \mathrm{~cm} / 24 \mathrm{~h}$ in the plants with Tecamin.

Basically similar results were obtained when determine the pace of leaf formation. Differences were found between the separate variants which were not statistically important. Highest was the number of the leaves formed for one day and night in the plants that were not fertilized with organic fertilizers - 0,55 pcs. of number $/ 24 \mathrm{~h}$ and those treated with Tecamin and Humustim 0,54 pcs. of number $/ 24 \mathrm{~h}$.

Generalizing the results that characterize the growth expressions of the plants grown in peatperlite substrate we could conclude that the studied bioproducts did not influence significantly over the studied biometric indexes. Complex with strongest growth expressions were the plants treated with Tecamin and Agriful. The variant of the cucumbers with applying Baykal had weakest growth indexes (Table 1).

Table 1. Biometric indexes of cucumbers Defense $F_{1}$ variety-peat-perlite substrate

\begin{tabular}{|c|c|c|c|c|c|c|}
\hline \multirow{2}{*}{ VARIANT } & \multicolumn{2}{|c|}{ Stem height, cm } & \multirow{2}{*}{$\begin{array}{c}\text { Growth pace } \\
\text { cm/24h/plant } \\
\text { Average } \\
\text { cm /day }\end{array}$} & \multicolumn{2}{|c|}{ Number of leaves } & \multirow{2}{*}{$\begin{array}{c}\text { Formation pace } \\
\text { number/24h/plant } \\
\text { Average } \\
\text { Number of leaves./day }\end{array}$} \\
\hline & $\begin{array}{l}\text { start } \\
\mathrm{cm}\end{array}$ & $\begin{array}{l}\text { end } \\
\mathrm{cm}\end{array}$ & & $\begin{array}{l}\text { start } \\
\text { number }\end{array}$ & $\begin{array}{l}\text { end } \\
\text { number }\end{array}$ & \\
\hline 1. Control & 66,88 & 219,56 & 4,32 n.s. & 12,82 & 32,29 & 0,55 n.s. \\
\hline 2. Baykal & 80,13 & 228,19 & 3,74 n.s. & 14,32 & 34,07 & 0,50 n.s. \\
\hline 3. BioOne & 67,90 & 218,17 & 4,27 n.s. & 12,79 & 31,18 & 0,52 n.s. \\
\hline 4. Tecamin & 68,27 & 224,89 & 4,46 n.s. & 13,32 & 32,32 & 0,54 n.s. \\
\hline 5. Agriful & 71,40 & 224,82 & 4,40 n.s. & 13,23 & 31,28 & 0,52 n.s. \\
\hline 6. Humustim & 72,71 & 226,46 & 4,38 n.s. & 13,50 & 32,68 & 0,54 n.s. \\
\hline 7. Labin & 68,92 & 211,79 & 4,06 n.s. & 12,46 & 31,32 & 0,53 n.s. \\
\hline
\end{tabular}




\section{Yield}

The highest first quality production yield was found in the cucumbers treated with Humustim $99550 \mathrm{~kg} / \mathrm{ha}$. The values that were obtained significantly exceed those of all other variants. The exception was the plants with mineral fertilizing and the cucumbers treated with Baykal where the observed excession of the values was not statistically based. The studied bioproducts for fertilizing did not increase significantly the first quality production in comparison with the control variant.
ARNAOUDOV B., et al.

Differences in the values from second quality production were not found; they vary from 45830 $\mathrm{kg} / \mathrm{ha}$ in the control to $57770 \mathrm{~kg} / \mathrm{ha}$ in the plants treated with Baykal.

The registered total yield of cucumbers treated with Humustim had the greatest measurement $157520 \mathrm{~kg} / \mathrm{ha}$. It significantly exceeded the rest of the variants with exception of those in which the bioproducts Baykal (149710 kg/ha) and Tecamin $(137940 \mathrm{~kg} / \mathrm{ha})$ were introduced. The values of the yield in variant with BioOne $(133120 \mathrm{~kg} / \mathrm{ha})$ were lowest. The results that were obtained are shown in Figure 1.

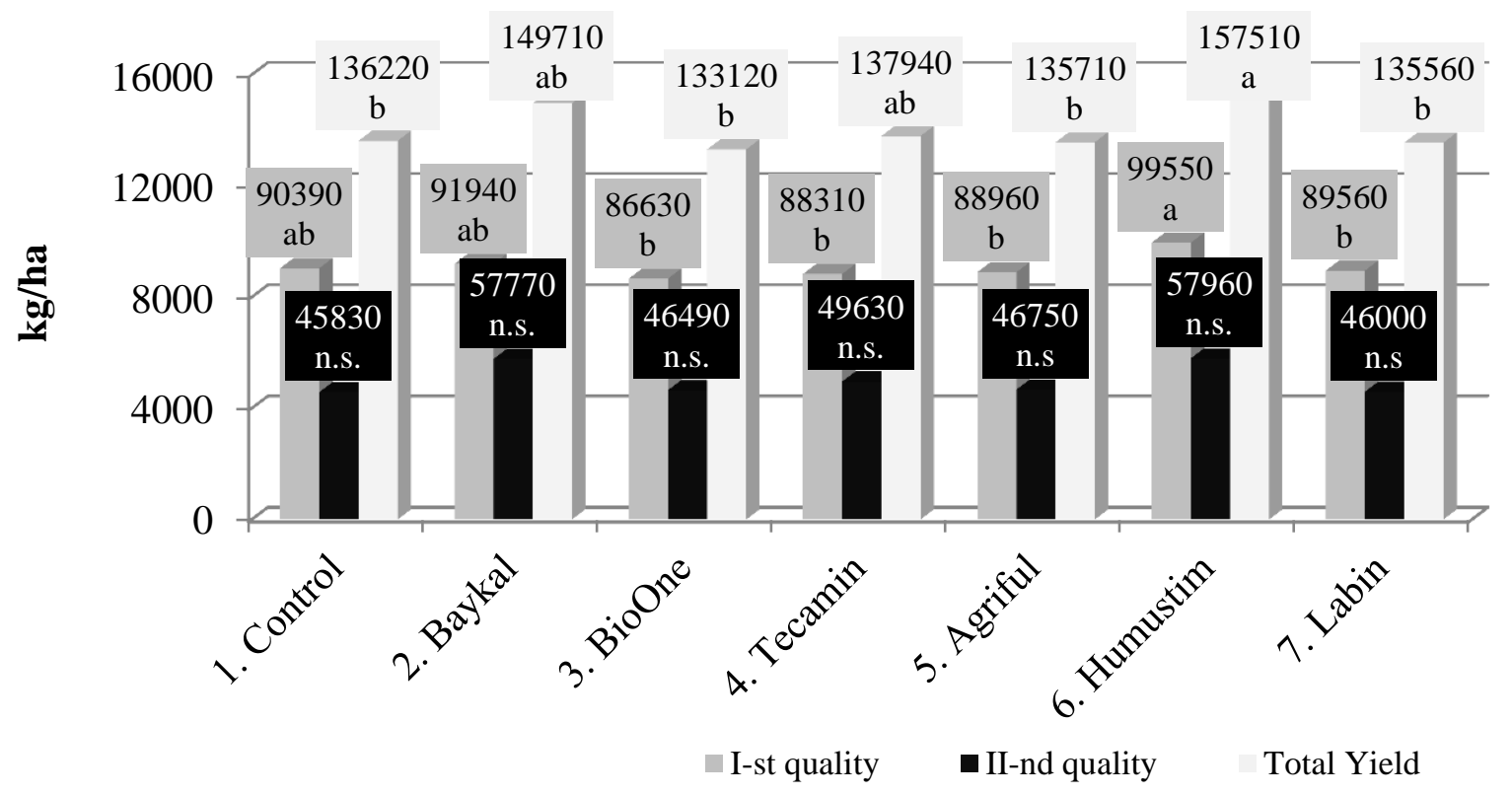

Figure 1. Yield of cucumber Defense $F_{1}$ variety grown in peat: perlite substrate

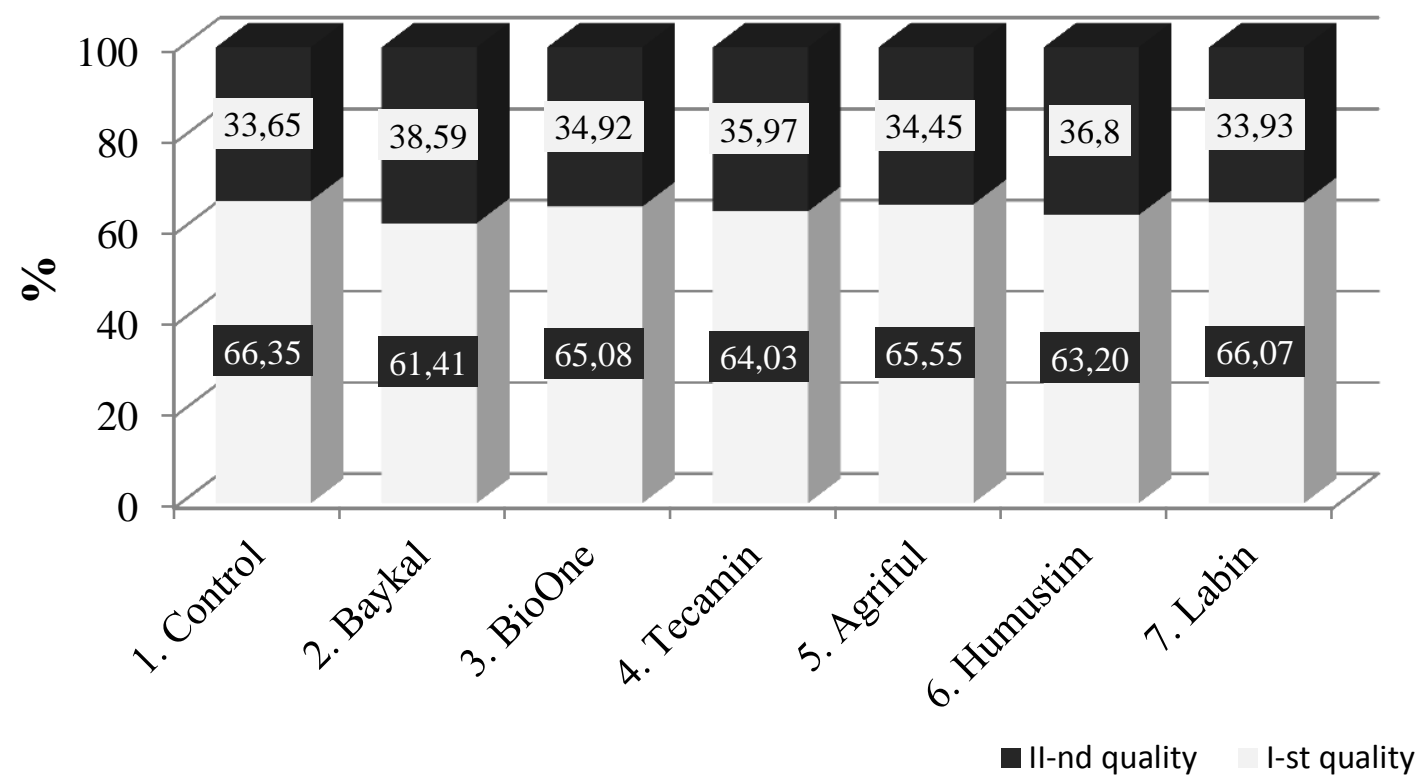

Figure 2. Percent distribution of the yield by quality 
The studied bioproducts did not influence significantly over the percentage correlation between the production from first and second quality in comparison with the control $(66,35$ $\%$ of the total yield). The values of that index in the variants with bioproducts vary from $66,07 \%$ in the cucumbers treated with Labin to $61,41 \%$ in the plants fertilized with Baykal

(Figure 2).

\section{CONCLUSION}

The experimented bioproducts did not influece significantly over the studied biometric indexes.

Adding Humustim to the nutrition regime of the glasshouse cucumbers increases the production from first quality $(99550 \mathrm{~kg} / \mathrm{ha})$. The quantity of the yield was not influenced by the use of the studied fertilizing bioproducts. The treatment with Humustim did not significantly increase the total yield in comparison with the conventional fertilizing but it had a significantly higher influence over the productivity of the rest of the fertilizing bioproducts. As a result of adding organic fertilizers to the nutrition regime the percentage distribution of the production from the first quality did not increase.

\section{REFERENCES}

ARNAOUDOV B., et al.

1. Chen, Y. And T. Aviad. 1990. Effects of humic substances on plant growth. In: McCarthy, P., Calpp, C.E., Malcolm, R.L., Bloom, P.R. (eds.), Humic Substances in Soil and Crop Sciences: Selected Readings. ASA and SSSA, Madison, WI, pp. 161-186.

2. Friedel, J.K. and E. Scheller. 2002. Composition of hydrolysable amino acids in soil organic matter and soil microbial biomass. Soil Biol. Biochem. 34, 315-325.

3. Gunes A., A. İnal, M. Aktas. 1996. Reducing nitrate content of NFT grown winter onion plants (Allium cepa L.) by partial replacement of $\mathrm{NO}_{3}$ with amino acid in nutrient solution. Scientia Horticulturae. Vol. 65, Issues 2-3, June 1996, p. 203-208

4. Gunes Aydin Gunes, Wietse N. K. Post, Ernest A. Kirkby \& Mehmet Aktas; Influence of partial replacement of nitrate by amino acid nitrogen or urea in the nutrient medium on nitrate accumulation in NFT grown winter lettuce. Journal of Plant Nutrition Vol. 17, Issue 11 p. 1929-1938 | Published online: 21 Nov 2008

5. Knicker, H., et al. 1993. The chemical nature of nitrogen in native soil organic matter. Naturwissenschaften 80, 219-221. 